\title{
Transapical transcatheter aortic valve replacement for aortic regurgitation with a second-generation heart valve
}

Huan Liu, MD, ${ }^{\mathrm{a}}$ Ye Yang, MD, ${ }^{\mathrm{a}}$ Wenshuo Wang, MD, ${ }^{\mathrm{a}} \mathrm{Da} \mathrm{Zhu}, \mathrm{MD},{ }^{\mathrm{b}}$ Lai Wei, MD, ${ }^{\mathrm{a}}$ Kefang Guo, MD, Weipeng Zhao, MD, ${ }^{\mathrm{d}}$ Xue Yang, MD, ${ }^{\mathrm{e}}$ Liming Zhu, MD, ${ }^{\mathrm{a}}$ Yingqiang Guo, MD, ${ }^{\mathrm{b}}$ Wei Wang, MD, ${ }^{\mathrm{f}}$ and Chunsheng Wang, $\mathrm{MD}^{\mathrm{a}}$

\section{ABSTRACT}

Objective: To report on the Chinese multicenter study of the J-Valve transcatheter heart valve for treatment of predominant aortic regurgitation.

Methods: Transapical transcatheter aortic valve replacement with the J-Valve for treating high-risk severe aortic regurgitation was performed in 43 patients in 3 Chinese centers. The study was registered with the Chinese Clinical Trial Registry (ChiCTR-OPC-15006354). Procedural results and clinical outcomes up to 1-year were analyzed using Valve Academic Research Consortium 2 criteria.

Results: All patients (mean age, $73.9 \pm 5.7$ years) were considered at prohibitive or high risk for surgical valve replacement (logistic European System for Cardiac Operative Risk Evaluation, $20.0 \%$ to $44.4 \%$; mean, $25.5 \% \pm 5.3 \%$ ) after evaluation by an interdisciplinary heart team. Transapical implantation was successful in 42 patients $(97.7 \%)$. The 1-year outcomes included all-cause mortality $(4.7 \%)$, disabling stroke $(2.3 \%)$, new permanent pacemaker $(4.7 \%)$, and valve-related reintervention $(7.0 \%)$. At the 1-year follow-up, postprocedural paravalvular regurgitation was none/trace in 30 of 39 patients and mild in 8 of 39 patients, and the mean transvalvular gradient after valve implantation was favorable at $10.4 \pm 4.5 \mathrm{~mm} \mathrm{Hg}$.

Conclusions: After an initial demonstration of feasibility, this multicenter study shows that the J-Valve transcatheter heart valve system is a reasonable option for patients with predominant aortic regurgitation. ( $\mathrm{J}$ Thorac Cardiovasc Surg 2018;156:106-16)

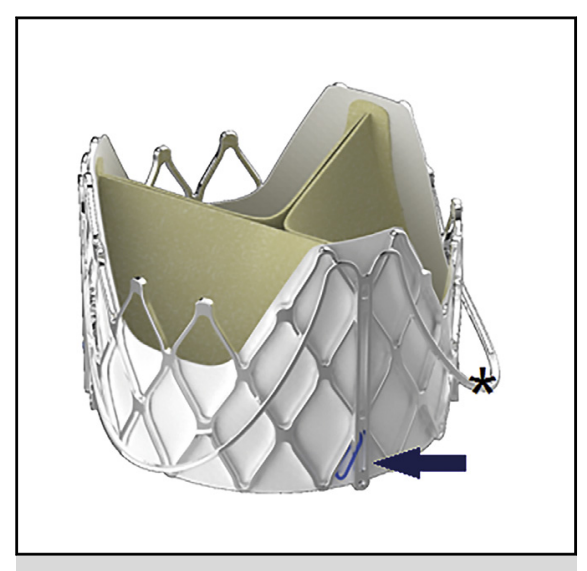

Schematic drawing of the J-Valve device.

\section{Central Message}

We report 1-year outcomes of a multicenter study of the J-Valve in treating 43 patients with noncalcified predominant aortic regurgitation with excellent outcomes.

\section{Perspective}

Transcatheter aortic valve replacement in patients with predominant aortic regurgitation is a technical challenge in clinical practice. We report 1 -year outcomes of a multicenter study on use of the J-Valve device in treating 43 patients with noncalcified predominant aortic regurgitation. Owing to the special design of this device, accurate deployment and reinforced anchoring of the prosthesis result in excellent outcomes.

See Editorial Commentary page 117.
Transcatheter aortic valve replacement (TAVR) has been established as a, alternative treatment for patients with symptomatic severe aortic stenosis deemed at prohibitive or high risk for surgical aortic valve replacement

\footnotetext{
From the Departments of ${ }^{\mathrm{a}}$ Cardiovascular Surgery and ${ }^{\mathrm{d}}$ Echocardiography, Shanghai Cardiovascular Institution and Zhongshan Hospital, and Departments of ${ }^{\mathrm{c}}$ Anesthesiology and ${ }^{\mathrm{e}}$ Medical Imaging, Zhongshan Hospital, Fudan University, Shanghai, China; ${ }^{b}$ Department of Cardiac Surgery, West China Hospital, Sichuan University, Chengdu, China; and ${ }^{\mathrm{f}}$ Department of Cardiac Surgery, Fuwai Cardiovascular Hospital, Chinese Academy of Medical Sciences and Peking Union Medical College, Beijing, China.

Drs Liu, Yang, and Wang contributed equally to this work.
}

(SAVR). ${ }^{1-3}$ Off-label uses of TAVR for treatment of native predominant aortic regurgitation has been reported with several devices. ${ }^{4-10}$ Overall outcomes of these studies were basically promising; however, outcomes

Received for publication July 9, 2017; revisions received Dec 16, 2017; accepted for publication Dec 27, 2017; available ahead of print March 7, 2018.

Address for reprints: Lai Wei, MD, No. 1609 Xietu Rd, Building 16, Room 639,

Shanghai, China 200032 (E-mail: wl_heartsurgeon@126.com). 0022-5223/\$36.00

Copyright $(\subset) 2018$ by The American Association for Thoracic Surgery https://doi.org/10.1016/j.jtcvs.2017.12.150 


\section{Abbreviations and Acronyms \\ $\mathrm{AVB}=$ atrioventricular block \\ BPD = balloon postdilation \\ EuroSCORE $=$ European System for Cardiac \\ Operative Risk Evaluation \\ LVOT = left ventricular outflow tract \\ MDCT = multidetector computed tomography \\ PVL = paravalvular leak \\ SAVR $=$ surgical aortic valve replacement \\ TAVR $=$ transcatheter aortic valve replacement \\ TEE $\quad=$ transesophageal echocardiography \\ THV $=$ transcatheter heart valve}

Scanning this QR code will take you to the supplemental videos for the article.

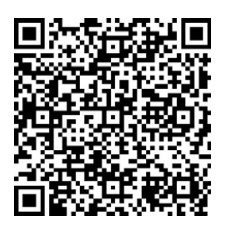

varied significantly among studies using different devices.

For most devices, aortic regurgitation characterized by an absence of calcification and relatively larger annuli, poses a technological challenge because of questionable anchoring, which can lead to high incidences of valve migration and paravalvular leak. The experience with first-generation transcatheter valves in treating aortic regurgitation was unsatisfactory. In recent years, the second-generation transcatheter valves featuring specific positioning and anchoring mechanisms have emerged as promising alternatives. TAVR with these devices, including the JenaValve (JenaValve Technology, Munich, Germany) and Engager valve (Medtronic, Minneapolis, Minn), to treat pure aortic regurgitation has shown encouraging results, but the experience remains limited. ${ }^{8,11}$

The J-Valve system (JieCheng Medical Technology Co, Ltd, Suzhou, China) is a second-generation self-expanding transcatheter heart valve (THV) with a unique 2-piece structure that consists of a 3-prong clasper and a support frame connected to each other with 3 stitches (Figure 1). The process of J-Valve deployment in vitro is shown in Figure 2, A-H. Its distinctive 2-stage implantation and the feasibility of transapical implantation in aortic regurgitation have been reported in previous studies, and early outcomes have been encouraging (Figure 2, $I-K$ ). ${ }^{12-15}$ Here we report the 1-year outcomes of the first multicenter study of transapical implantation of the J-Valve system for treatment of predominant aortic regurgitation in patients considered at prohibitive or high surgical risk.

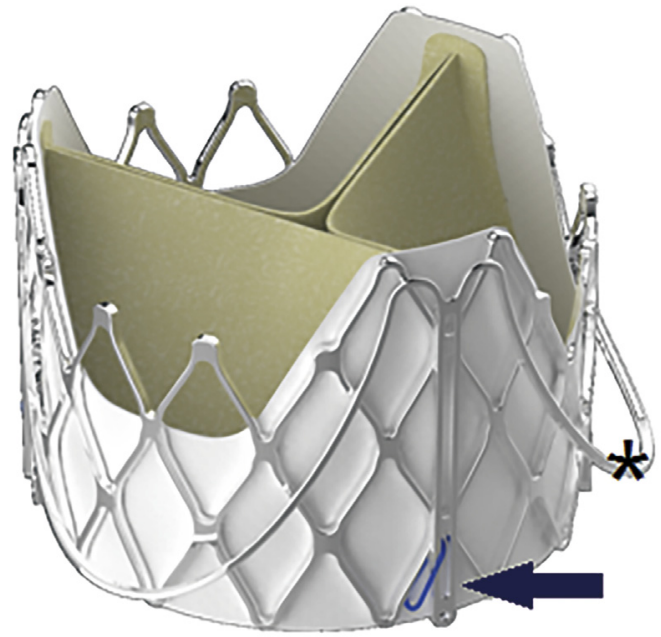

FIGURE 1. Schematic drawing of the J-Valve prosthesis. The support frame and 3-prong clasper (asterisk) are connected with 3 sutures (arrow), resulting in a movable connection.

\section{METHODS}

\section{Patients and Preoperative Evaluation}

Between March 2014 and July 2015, 43 patients with predominant aortic valve regurgitation were enrolled for transapical implantation of the J-Valve system in 3 Chinese centers, including 16 patients at Zhongshan Hospital, Fudan University; 23 patients at West China Hospital, Sichuan University; and 4 patients at Fuwai Cardiovascular Hospital, Chinese Academy of Medical Sciences and Peking Union Medical College. A single surgeon from each center performed all of the operations in this series. No surgeon treated any cases at any different sites. All patients were evaluated by a multidisciplinary heart team before admission. Prohibitive risk was defined as an estimated probability of death or serious irreversible morbidity after SAVR of $>50 \%$. Patients age $\geq 60$ years and at increased surgical risk, as defined by a logistic EuroSCORE (European System for Cardiac Operative Risk Evaluation) $\geq 20 \%$, were scheduled for TAVR. The addition of specific clinical and anatomic variables that affect mortality, ${ }^{16}$ such as frailty, major organ system compromise, and procedure-specific impediment were routinely considered in patient evaluation.

A routine workup with transthoracic echocardiography and contrastenhanced multidetector computed tomography (MDCT) was performed (Figure 3). Patients with an aortic sinus or ascending aorta diameter $>50 \mathrm{~mm}$ or an annulus diameter $>29 \mathrm{~mm}$ were excluded. Clinical and anatomic evaluations with these modalities have been described in detail previously. $^{13}$

\section{Procedure}

The procedure was performed in a hybrid operating room with the patient under general anesthesia. Transesophageal echocardiography (TEE) was performed to further evaluate the anatomic features of the aortic annulus and provide additional information during valve positioning and deployment (Figure 4). TEE is helpful in determining the native valve position and confirming the coaxiality between the prosthesis and the left ventricular outflow tract (LVOT). Although cardiopulmonary bypass was not necessary in most cases, it was available on standby during all cases. 

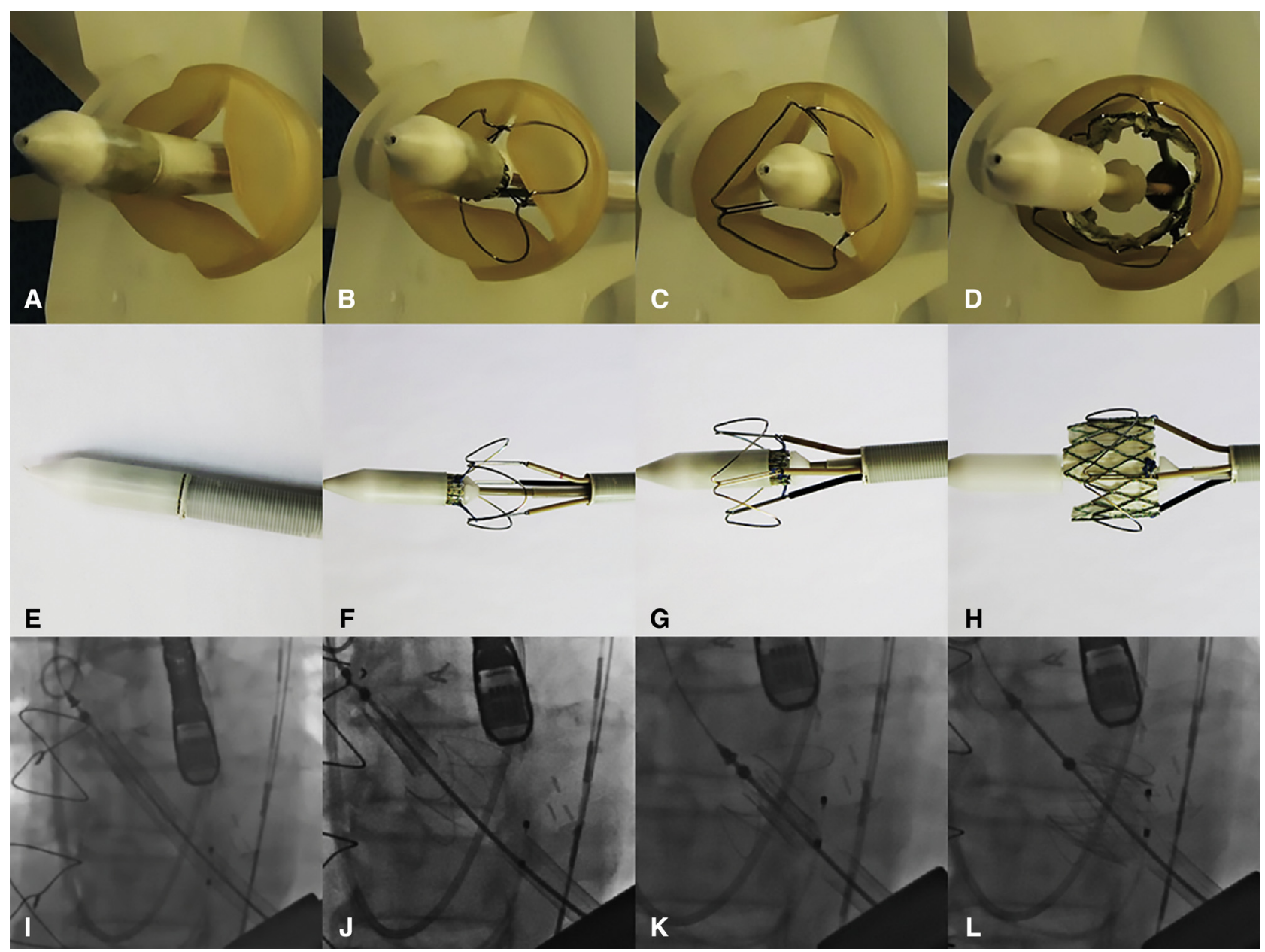

FIGURE 2. Demonstration of valve deployment and release from the delivery system. The valve deployment process was demonstrated in vitro with (A-D) and without (E-H) a heart model and in vivo with fluroscopy (I-L). A, E, and I, The original status of the prosthesis. B, F, and J, The clasper deployed and seated into the aortic sinus. C, G, and K, The transcatheter heart valve (THV) descended into the aortic annulus. D, H, and L, The THV deployed into the aortic annulus.

During the procedure, a limited left thoracotomy was made. Two 3-0 polypropylene (Ethicon, Somerville, NJ) Teflon-reinforced mattress sutures were placed on the left ventricle apex, and the patient was heparinized to Maintain the activated clotting time $>300$ s. The delivery system was inserted into the left ventricle through the apex and then across the aortic valve over a standard polytetrafluoroethylene-coated EMERALD guidewire (Cordis, Miami Lakes, Fla). The implantation process consisted of 2 stages: positioning of the clasper, followed by lowering and deployment of the prosthesis.

Given the absence of valve calcification in aortic regurgitation, identification of the aortic sinus and annulus relies on root angiography. The level of the cusp nadir should be marked on the screen once root angiography is completed. Once the clasper is deployed in the aortic root, it is pulled downward and seated into the aortic sinus. A repeat root angiography is performed to confirm the position and configuration of the clasper. Because of the low profile of the clasper, cine imaging with higher energy is preferred to depict the detailed configuration of the clasper (Videos 1 and 2). The technique has been described in detail previously. ${ }^{13}$

\section{Data Management and Clinical Follow-up}

The prospectively collected baseline, procedural, and follow-up data were reviewed. Comprehensive clinical and echocardiographic assessments were scheduled before discharge and at 30 days, 6 months, and 1 year after the procedure. Outcomes were analyzed in accordance with updated standardized endpoints defined by the Valve Academic Research Consortium $2 .^{17}$

\section{Ethics}

This prospective, multicenter, nonrandomized single-arm clinical study was approved by the Chinese Food and Drug Administration. This study was performed at 3 clinical sites in China. Local Ethics Committees approved the study protocol at the respective centers in accordance with the principles of the Declaration of Helsinki. The study was registered with the Chinese Clinical Trial Registry (ChiCTR-OPC-15006354). All patients were fully informed about the procedure and its experimental use of THV (at the time of implantation). All patients provided signed written consent.

\section{Statistics}

Normally distributed continuous variables are presented as mean \pm standard deviation; non-normally distributed variables, as median and range; and categorical variables, as number and percentage. Survival was investigated using Kaplan-Meier analysis, and differences in survival and freedom from composite endpoint of death and reintervention between groups were examined with the log-rank test. All statistical analyses were performed with SAS version 9.2 (SAS Institute, Cary, NC). 

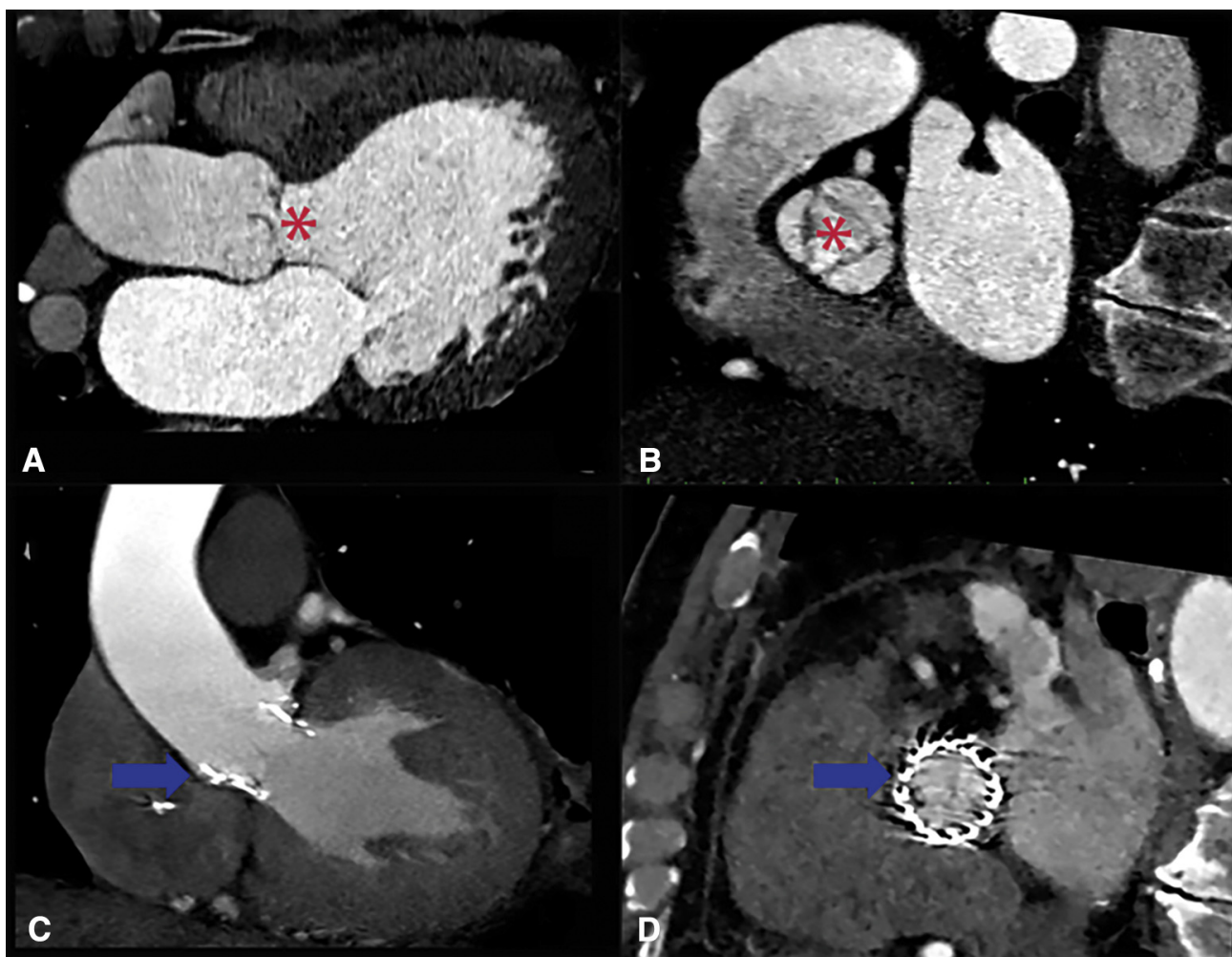

B
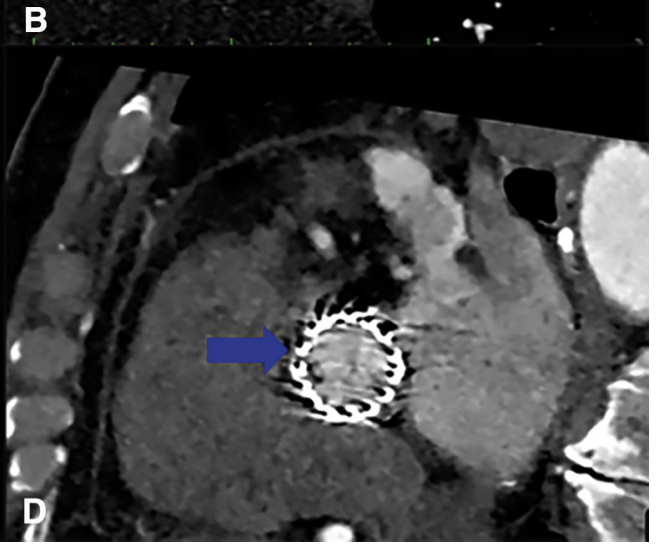

FIGURE 3. Preoperative and postoperative multidetector computed tomography. A and B, Reconstruction of the aortic root before transcatheter heart valve (THV) implantation. There was no calcification on the native aortic valve (asterisks). C and D, Reconstruction of the aortic root after THV implantation (arrows).
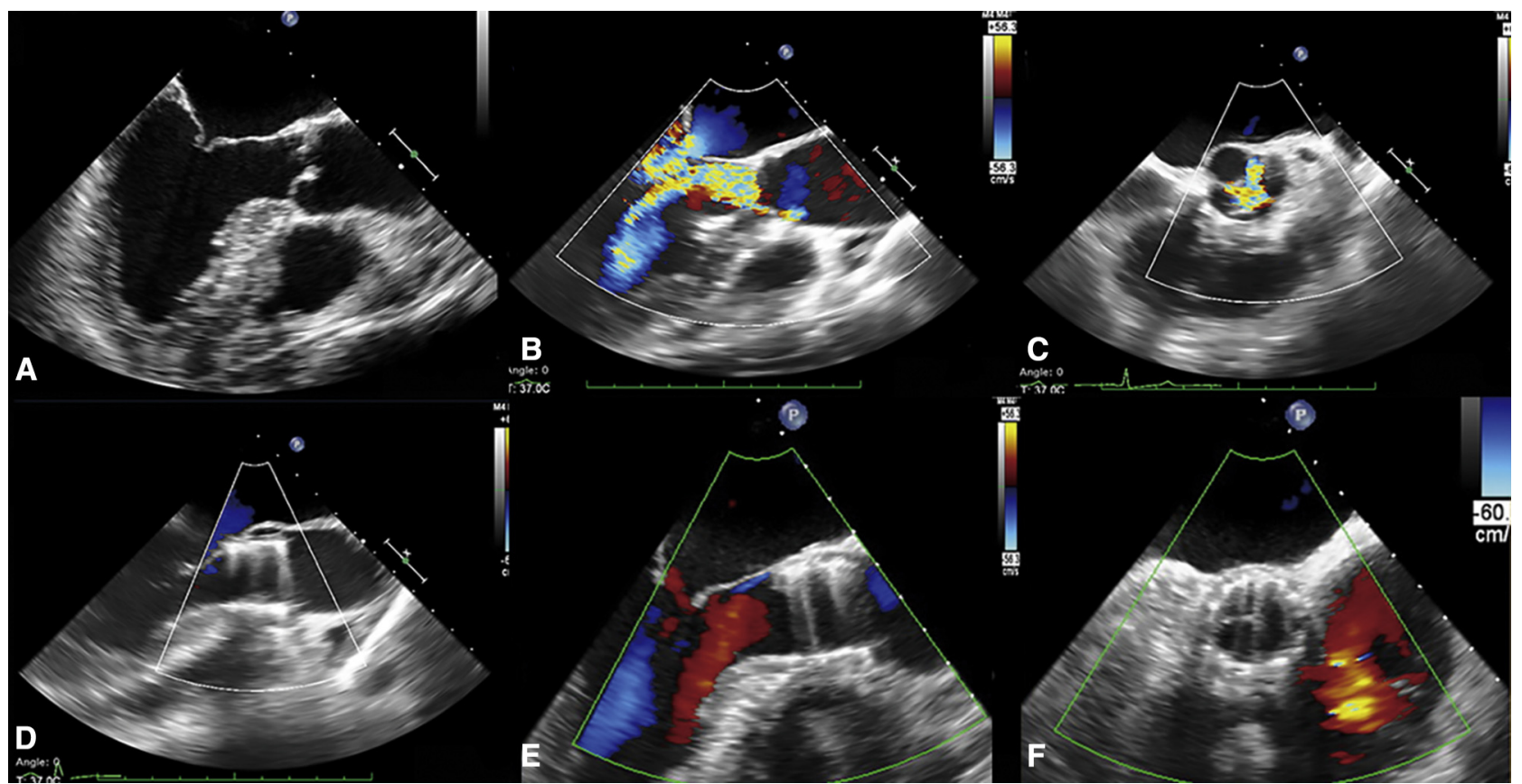

A

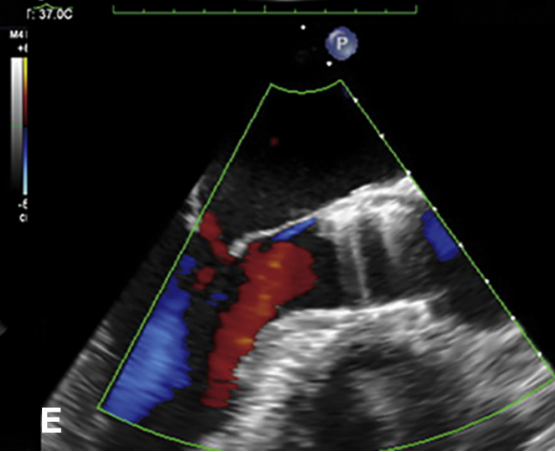

FIGURE 4. Transesophageal echocardiography (TEE) during the procedure. A-C, TEE of native aortic valve before transcatheter heart valve (THV) implantation. D-F, TEE of aortic valve after THV implantation. 


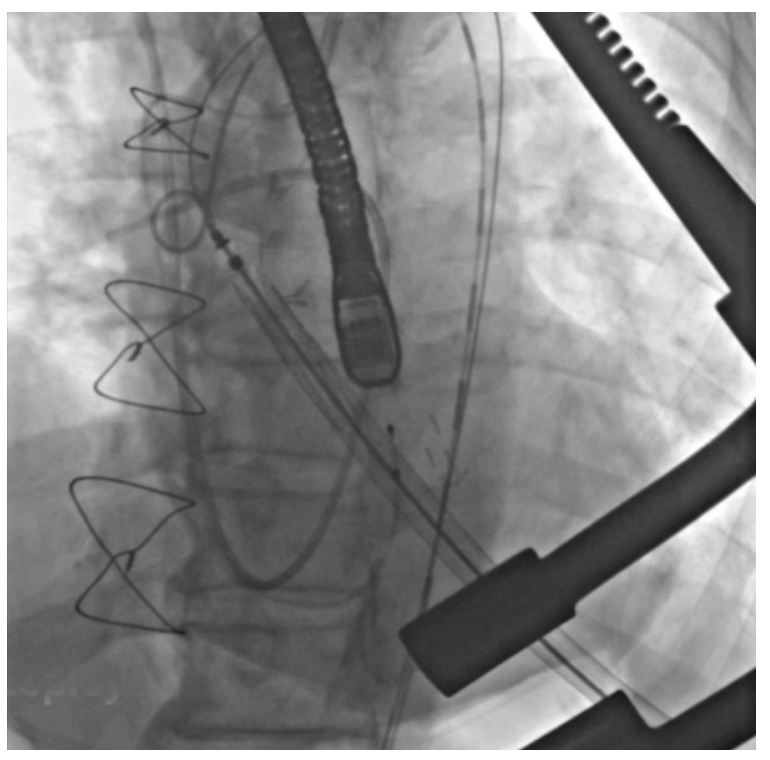

VIDEO 1. J-Valve implantation in a patient with predominant aortic regurgitation. Video available at: http://www.jtcvsonline.org/article/ S0022-5223(18)30367-2/fulltext.

\section{RESULTS}

\section{Patient Demographics}

Baseline patient characteristics are summarized in Table 1. All 43 patients had aortic regurgitation of at least moderate grade with symptoms of left ventricular dysfunction. Two patients had congenital bicuspid aortic valves, and 41 had tricuspid aortic valves. According to the definitions published in recent guidelines, ${ }^{18} 2$ patients had moderate aortic stenosis, 19 had mild aortic stenosis, and the other 22 had no aortic stenosis. No patient had aortic valve or LVOT calcification, defined as any voxel $>130$ Hounsfield units on non-contrast-enhanced MDCT. Three patients $(7.0 \%)$ had preoperative first-degree atrioventricular block (AVB). One patient had a history of off-pump coronary artery bypass surgery, and 1 patient had an implanted freestyle aortic root bioprosthesis. Preoperatively, all patients were evaluated by an

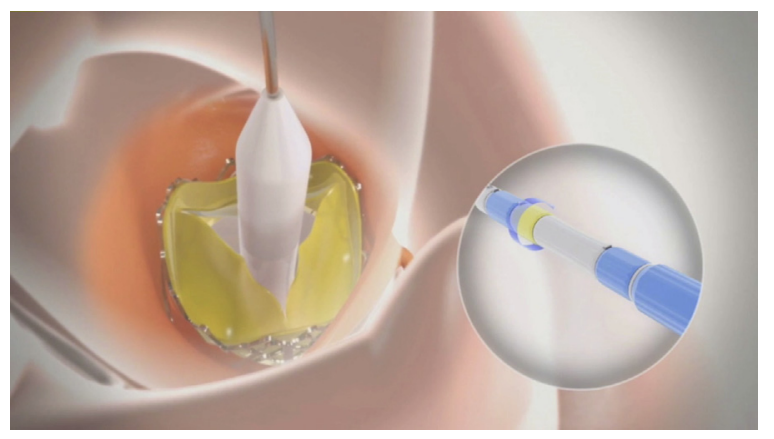

VIDEO 2. The scene in the operating theater during the procedure, and the steps of the implantation process. Video available at: http://www. jtcvsonline.org/article/S0022-5223(18)30367-2/fulltext.
TABLE 1. Baseline clinical parameters

\begin{tabular}{|c|c|}
\hline Parameter & Value \\
\hline Age, $y$, mean $\pm S D$ & $73.9 \pm 5.7$ \\
\hline Male sex, n (\%) & $30(69.8)$ \\
\hline BMI, $\mathrm{kg} / \mathrm{m}^{2}$, mean $\pm \mathrm{SD}$ & $22.5 \pm 3.2$ \\
\hline Smoking, n (\%) & $7(16.3)$ \\
\hline Systemic hypertension, $\mathrm{n}(\%)$ & $32(74.4)$ \\
\hline Diabetes mellitus, n (\%) & $4(9.3)$ \\
\hline Hyperlipidemia, n (\%) & $1(2.3)$ \\
\hline Peripheral vascular disease, $\mathrm{n}(\%)$ & $20(46.5)$ \\
\hline Cerebrovascular disease, $\mathrm{n}(\%)$ & $27(62.8)$ \\
\hline Previous stroke, $\mathrm{n}(\%)$ & $4(9.3)$ \\
\hline Atrial fibrillation, $\mathrm{n}(\%)$ & $6(14.0)$ \\
\hline Chronic lung disease, $\mathrm{n}(\%)$ & $25(58.1)$ \\
\hline Serum creatinine, $\mathrm{mg} / \mathrm{dL}$, mean $\pm \mathrm{SD}$ & $1.0 \pm 0.3$ \\
\hline Anemia, n (\%) & $14(32.6)$ \\
\hline Coronary artery disease, $\mathrm{n}(\%)$ & $5(11.6)$ \\
\hline Recent myocardial infarction (within $30 \mathrm{~d}), \mathrm{n}(\%)$ & 0 \\
\hline Previous coronary artery bypass graft, $\mathrm{n}(\%)$ & $1(2.3)$ \\
\hline Previous valve surgery, n (\%) & $1(2.3)$ \\
\hline NYHA functional class >III, n (\%) & $14(32.6)$ \\
\hline Ascending aortic diameter, $\mathrm{mm}$, mean $\pm \mathrm{SD}$ & $39.0 \pm 4.9$ \\
\hline \multicolumn{2}{|l|}{ Etiology, n (\%) } \\
\hline Degenerative & $31(72.1)$ \\
\hline Rheumatic & $10(23.2)$ \\
\hline Bicuspid & $2(4.7)$ \\
\hline \multicolumn{2}{|l|}{ Aortic regurgitation grade, $\mathrm{n}(\%)$} \\
\hline None or mild & 0 \\
\hline Moderate & 0 \\
\hline Moderate to severe & $13(30.2)$ \\
\hline Severe & $30(69.8)$ \\
\hline Aortic $V_{\max }, \mathrm{m} / \mathrm{s}$, mean $\pm \mathrm{SD}$ & $2.0 \pm 0.6$ \\
\hline Aortic mean $\Delta \mathrm{P}, \mathrm{mm} \mathrm{Hg}$, mean $\pm \mathrm{SD}$ & $9.5 \pm 5.2$ \\
\hline MR moderate or greater, $\mathrm{n}(\%)$ & $4(9.3)$ \\
\hline LVEF, $\%$, mean \pm SD & $55.9 \pm 10.8$ \\
\hline LVEDD, mm, mean $\pm \mathrm{SD}$ & $60.5 \pm 8.4$ \\
\hline $\log \mathrm{ES}, \%$, mean $\pm \mathrm{SD}$ & $25.5 \pm 5.3$ \\
\hline
\end{tabular}

SD, Standard deviation; BMI, body mass index; NYHA, New York Heart Association; $V_{\max }$, maximum aortic velocity; $\Delta P$, pressure gradient; $M R$, mitral regurgitation; $L V E F$, left ventricular ejection fraction; $L V E D D$, left ventricular end-diastolic diameter; $\log E S$, logistic European System for Cardiac Operative Risk Evaluation (EuroSCORE).

interdisciplinary heart team and deemed to be at prohibitive or high risk for SAVR. The mean logistic EuroSCORE ${ }^{7}$ was $25.5 \% \pm 5.3 \%$. This group of patients presented with a truly high-risk profile, with high prevalences of chronic lung disease $(\mathrm{n}=25 ; 58.1 \%)$, peripheral vascular disease $(\mathrm{n}=20 ; 46.5 \%)$, and cerebrovascular disease $(\mathrm{n}=27$; $62.8 \%)$. 
TABLE 2. Procedure outcomes and detailed valve function immediately after implantation

\begin{tabular}{|c|c|}
\hline Outcome & Value \\
\hline \multicolumn{2}{|l|}{ Aortic annulus diameter, mm, mean $\pm \mathrm{SD}$ (n) } \\
\hline TTE & $23.1 \pm 2.0(43)$ \\
\hline MDCT & $25.2 \pm 1.5(43)$ \\
\hline MDCT area-derived & $24.8 \pm 1.5(38)$ \\
\hline MDCT STJ diameter, mm, mean \pm SD (n) & $38.0 \pm 5.4(43)$ \\
\hline MDCT LCA ostium height, mm, mean \pm SD (n) & $13.3 \pm 3.5(43)$ \\
\hline MDCT RCA ostium height, mm, mean \pm SD (n) & $15.5 \pm 5.1(43)$ \\
\hline Contrast agent, mL, mean $\pm \mathrm{SD}(\mathrm{n})$ & $92.5 \pm 44.0(43)$ \\
\hline Successful implantation, n (\%) & $42(97.7)$ \\
\hline Conversion to SAVR, n (\%) & $1(2.3)$ \\
\hline \multicolumn{2}{|l|}{ THV size, $n(\%)(n=42)$} \\
\hline $25 \mathrm{~mm}$ & $13(31.0)$ \\
\hline $27 \mathrm{~mm}$ & $29(69.0)$ \\
\hline Postdilation, n (\%) & $2(4.7)$ \\
\hline Combined PCI, n (\%) & $1(2.3)$ \\
\hline Coronary obstruction, $\mathrm{n}$ & 0 \\
\hline Annulus rupture, $\mathrm{n}$ & 0 \\
\hline Transfusion & $1(2.3)$ \\
\hline \multicolumn{2}{|l|}{ Paravalvular aortic regurgitation, $n(\%)(n=42)$} \\
\hline None & $16(38.1)$ \\
\hline Trace & $15(35.7)$ \\
\hline Mild & $10(23.8)$ \\
\hline Moderate & $1(2.4)$ \\
\hline \multicolumn{2}{|l|}{ Intravalvular regurgitation, $n(\%)(n=42)$} \\
\hline None & $42(100)$ \\
\hline Mean aortic valve gradient, $\mathrm{mm} \mathrm{Hg}$, mean $\pm \mathrm{SD}$ (n) & $7.0 \pm 2.8(42)$ \\
\hline
\end{tabular}

\section{Procedural Outcomes}

Procedural outcomes and valve function data immediately after implantation are provided in Table 2. One patient was converted to SAVR due to valve embolism into the aortic arch. The other 42 cases were performed without cardiopulmonary bypass. No rapid pacing was necessary. No balloon predilation was necessary. Two patients without preoperative aortic stenosis underwent balloon postdilation (BPD) due to significant paravalvular leak (PVL) owing to frame underexpansion. No second valve was implanted in any case. No third-degree AVB, myocardium infarction, or cerebrovascular events occurred during the procedures.

The amount of contrast varied between $43 \mathrm{~mL}$ and $220 \mathrm{~mL}$ (mean dose, $92.5 \pm 44.0 \mathrm{~mL}$ ). After the MDCT was introduced to determine the optimal angle for angiography and the learning curve was conquered, the mean contrast dose was reduced to $\sim 60 \mathrm{~mL}$.
TABLE 3. 30-day and 1-year clinical endpoints $(n=43)$

\begin{tabular}{|c|c|c|}
\hline Endpoint & $30 \mathrm{~d}, \mathbf{n}(\%)$ & $1 \mathbf{y}, \mathbf{n}(\%)$ \\
\hline All-cause mortality & $1(2.3)$ & $2(4.7)$ \\
\hline Myocardial infarction & 0 & 0 \\
\hline \multicolumn{3}{|c|}{ Stroke or transient ischemic attack } \\
\hline Stroke & 0 & $1(2.3)$ \\
\hline Transient ischemia attack & 0 & 0 \\
\hline Bleeding complications & 0 & 0 \\
\hline \multicolumn{3}{|l|}{ Acute kidney injury } \\
\hline Stage 1 & $2(4.7)$ & $2(4.7)$ \\
\hline Stage 3 & $1(2.3)$ & $1(2.3)$ \\
\hline Vascular complications & 0 & 0 \\
\hline Permanent pacemaker & $1(2.3)$ & $2(4.7)$ \\
\hline Coronary obstruction & 0 & 0 \\
\hline Valve-related reintervention & $2(4.7)$ & $3(7.0)$ \\
\hline
\end{tabular}

Hemostasis was readily achieved in all patients. Only 1 patient needed intraoperative transfusion. THV function was assessed immediately after implantation by both TEE and angiography. No patient had intravalvular regurgitation or stenosis after THV implantation. One patient had moderate PVL, but in all other patients, PVL was no more than mild.

\section{Clinical Outcomes and Follow-up}

Detailed clinical outcomes at the 30-day and 1-year follow-ups are presented in Table 3. The median follow-up time was 362 days (range, 25-422 days). One patient with moderate PVL died of congestive heart failure 25 days after the operation. The patient had a bicuspid aortic valve and was in New York Heart Association (NYHA) grade IV before the operation. Another patient, who was converted to SAVR because of THV malposition, was discharged at postoperative day 7 and died of stroke 1 month after the operation. Forty-one patients survived to the latest follow-up, including 2 patients in NYHA functional class III and 39 patients $(95.1 \%)$ in NYHA class I or II. All patients showed significant improvement of symptoms of exertional dyspnea and exercise intolerance. The 1-year survivals free from all-cause mortality and the composite endpoint of death and reintervention were $95.3 \%$ and $90.7 \%$, respectively. Patients with greater than mild PVL and a preoperative logistic EuroSCORE $>30 \%$ showed a trend toward lower survival free from composite endpoint of death and reintervention, but this was not statistically significant (Figure 5).

No patient experienced myocardial infarction or any vascular complications during the follow-up. No new neurologic complications (including stroke and transient ischemic attack) occurred during the hospital stay. One patient who was converted to SAVR died of stroke at 

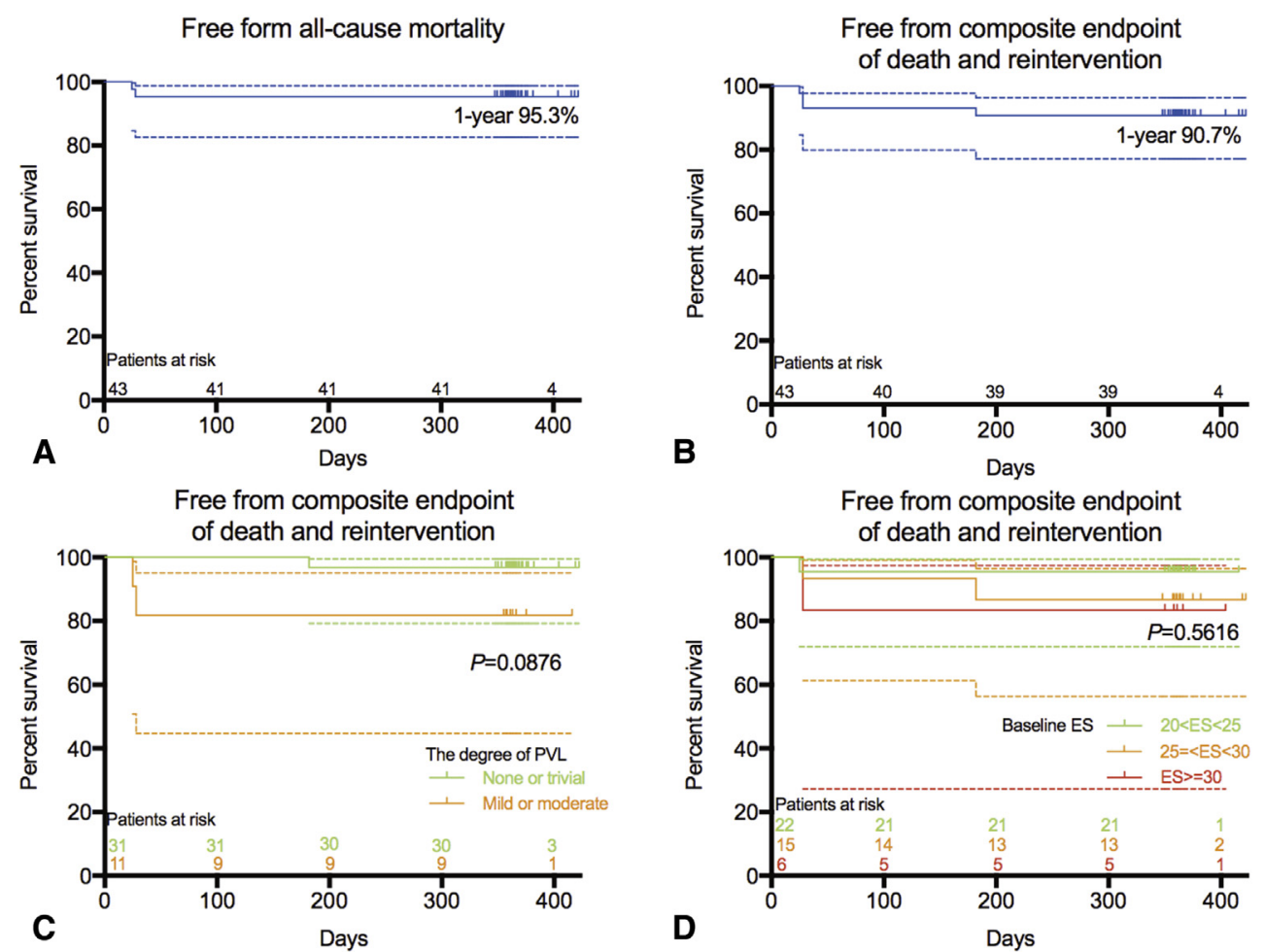

FIGURE 5. Kaplan-Meier estimates of survival probabilities. A, Percent survival free from all-cause mortality in the total cohort. B, Percent survival free from the composite endpoint of death and reintervention in the total cohort. C, Percent survival free from composite endpoint of death and reintervention by degree of paravalvular leak $(P V L)$. D, Percent survival free from the composite endpoint of death and reintervention by preoperative logistic EuroSCORE (ES).

home 1 month after the operation. No patient experienced major bleeding during or after the procedures. Only 1 patient required a blood transfusion during the hospital stay. According to the Acute Kidney Injury Network classification, ${ }^{19} 2$ patients had stage 1 acute kidney injury and 1 patient had stage 3 acute kidney injury necessitating hemodialysis. The mean serum creatinine concentration at postoperative day 7 was $1.0 \pm 0.3 \mathrm{mg} / \mathrm{dL}$.

Two patients developed third-degree AVB within 2 months after the procedure. One of these patients had an episode of syncope, and both patients received a permanent pacemaker. One patient with preoperative first-degree AVB had type 1 second-degree AVB at the latest follow-up. Ten patients developed first-degree AVB within 30 days, of whom 8 returned to normal conduction at the 1-year follow-up. No patient developed a new arrhythmia resulting in hemodynamic instability during hospital stay and follow-up. In addition, no wound complications occurred.

\section{Echocardiography Findings}

Results of follow-up echocardiography are summarized in Table 4. TEE was performed before discharge, 1 month, 6 months and 12 months after surgery. The degree of aortic regurgitation in baseline and the PVL during follow-up are shown in Figure 6. The mean gradients and peak velocities at baseline and after J-Valve implantation are illustrated in Figure 7.

\section{DISCUSSION}

Ever since its introduction into clinical practice in $2002,{ }^{20}$ TAVR has emerged as a valuable alternative treatment for patients with symptomatic severe aortic stenosis who deemed to be at high or prohibitive risk for SAVR. In latest studies with long-term follow-up, both balloon-expandable and self-expandable prostheses were proven superior to medical treatment in inoperable patients with aortic stenosis. ${ }^{1,21}$ In addition, evidence has shown that TAVR is not inferior to SAVR in terms of either safety or efficacy in high surgical risk patients. ${ }^{2,22}$ The current American College of Cardiology/American Heart Association guideline includes a class I recommendation of TAVR for patients deemed at prohibitive or high risk for SAVR. ${ }^{23}$

The indications for TAVR are expanding. Among the several additional indications for TAVR, treatment of predominant aortic regurgitation remains controversial and challenging. ${ }^{24}$ Off-label use of TAVR for treatment of aortic regurgitation without calcification has been reported with multiple devices..$^{4-6,8-10,12,13,25}$ Although feasibility and acceptable early outcomes have been confirmed by 
TABLE 4. Results of echocardiography at follow-up

\begin{tabular}{|c|c|c|c|c|}
\hline Result & Before discharge 3-10 d $(n=40)$ & $1 \mathrm{mo}(\mathrm{n}=40)$ & $6 \mathrm{mo}(\mathrm{n}=40)$ & 12 mo $(n=39)$ \\
\hline \multicolumn{5}{|c|}{ Aortic valve function, mean \pm SD } \\
\hline Peak velocity, m/s & $1.9 \pm 0.3$ & $2.0 \pm 0.4$ & $2.2 \pm 0.5$ & $2.2 \pm 0.5$ \\
\hline Mean gradient, $\mathrm{mm} \mathrm{Hg}$ & $8.6 \pm 3.0$ & $8.6 \pm 3.1$ & $11.2 \pm 7.7$ & $10.4 \pm 4.5$ \\
\hline \multicolumn{5}{|c|}{ Paravalvular aortic regurgitation, $\mathrm{n}(\%)$} \\
\hline None & $17(42.5)$ & $16(40.0)$ & $18(45.0)$ & $18(46.2)$ \\
\hline Trace & $12(30.0)$ & $10(25.0)$ & $11(27.5)$ & $12(30.7)$ \\
\hline Mild & $11(27.5)$ & $14(35.0)$ & $11(27.5)$ & $8(20.5)$ \\
\hline Moderate & 0 & 0 & 0 & $1(2.6)$ \\
\hline Severe & 0 & 0 & 0 & 0 \\
\hline \multicolumn{5}{|c|}{ Transvalvular aortic regurgitation, $\mathrm{n}(\%)$} \\
\hline None & $40(100)$ & $40(100)$ & $37(92.5)$ & $29(74.4)$ \\
\hline Trace & 0 & 0 & $3(7.5)$ & $8(20.5)$ \\
\hline Mild & 0 & 0 & 0 & $2(5.1)$ \\
\hline Moderate & 0 & 0 & 0 & 0 \\
\hline Severe & 0 & 0 & 0 & 0 \\
\hline \multicolumn{5}{|l|}{ Mitral regurgitation, n (\%) } \\
\hline None & $16(40.0)$ & $13(32.5)$ & $9(22.5)$ & $8(20.5)$ \\
\hline Trace & $14(35.0)$ & $17(42.5)$ & $20(50.0)$ & $20(51.3)$ \\
\hline Mild & $10(25.0)$ & $10(25.0)$ & $10(25.0)$ & $10(25.6)$ \\
\hline Moderate & 0 & 0 & $1(2.5)$ & $1(2.6)$ \\
\hline Severe & 0 & 0 & 0 & 0 \\
\hline
\end{tabular}

$S D$, Standard deviation.

these studies, the results varied significantly across different devices. First-generation TAVR devices were designed to dilate the stenotic aortic valve and to be securely anchored in calcified leaflet and annulus. Given the various anatomic features in patients with predominant aortic regurgitation, including absence of calcification, large annuli, and dilated aortic root and ascending aorta, the frequency of second valve implantation and incidence of PVL of more than moderate degree were relatively high when first-generation devices were used. Moreover, the risk of valve dislocation owing to insufficient anchoring and annular rupture due to excessive oversizing limits the use of these devices in this subset of patients. ${ }^{13}$

A series of second-generation TAVR devices with clip mechanism fixation, including the JenaValve, Engager valve, and J-Valve, have emerged as an alternative THV for aortic regurgitation. These devices share some features, including self-positioning and use of native leaflets to assist in THV position and fixation. ${ }^{26}$ The tissue valves are mounted in support frames surrounded by feelers, ${ }^{8}$ arches, ${ }^{11}$ and graspers $^{13}$ in these devices. These structures are designed to be placed into the sinus of the aortic root to

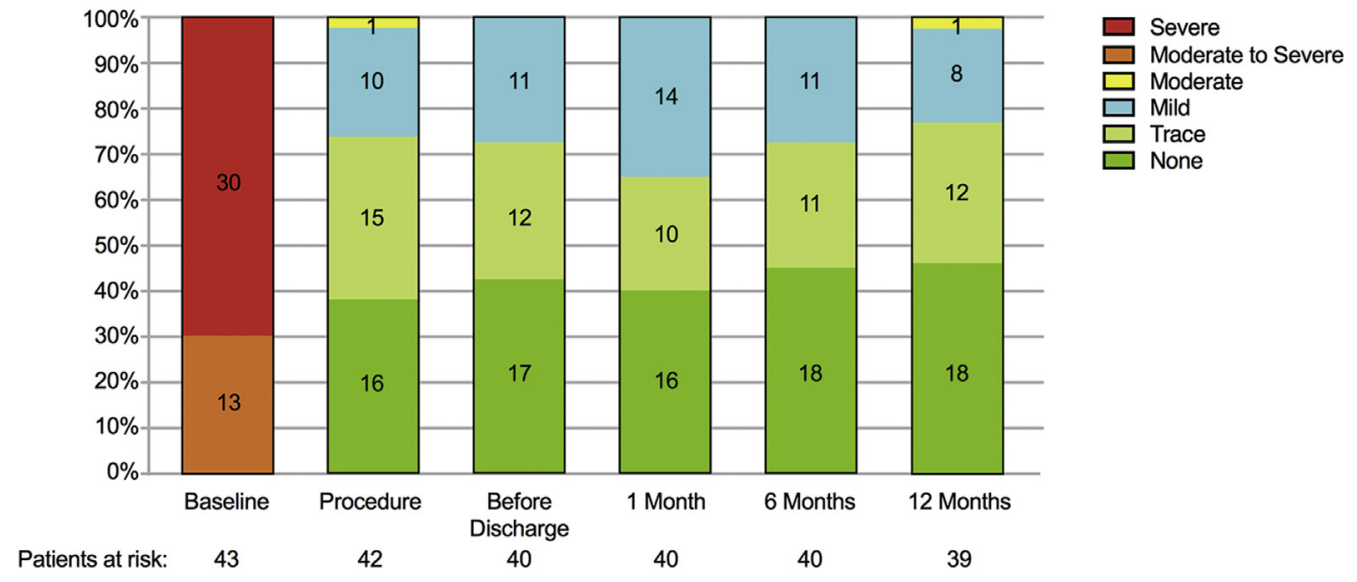

FIGURE 6. Aortic regurgitation at baseline and paravalvular leak after J-Valve implantation. 


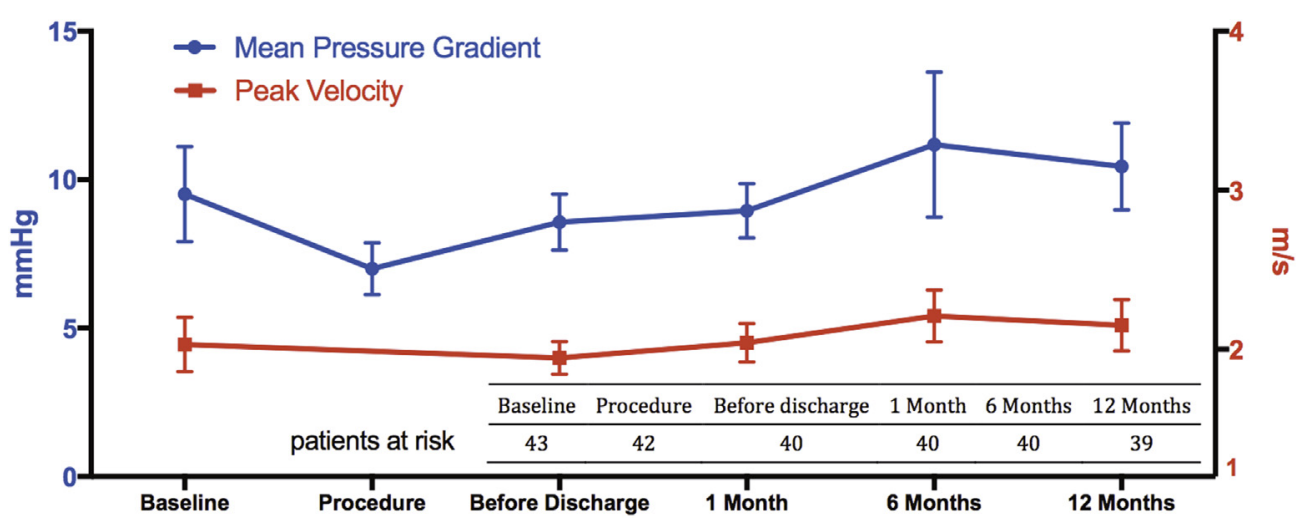

FIGURE 7. The mean gradients and peak velocities with $95 \%$ confidence limits at baseline and after J-Valve implantation.

achieve an anatomically correct position. Once the THVs are deployed, the native leaflets are clipped between the support frames and graspers (feelers or arches) to enforce the fixation. The feelers in the JenaValve and the arches in the Engager valve have a rigid connection with the support frames, whereas the J-Valve refines this approach by using mobile nitinol wire leaflet graspers to allow for fine positioning and active fixation to the leaflets. ${ }^{12}$ The use of these novel devices to treat aortic regurgitation using these novel devices is associated with decreased morbidity and mortality. ${ }^{27}$ In this study, we updated the 1 -year outcomes in patients who received a J-Valve implant to treat predominant aortic regurgitation without calcification. To the best of our knowledge, this multicenter study is the largest cohort of patients with aortic regurgitation treated with a second-generation THV reported to date.

Implantation was successful in 42 of 43 patients $(97.7 \%)$. One patient was converted to SAVR due to valve dislodgement. This occurred in one of our early procedures, with suboptimal fluorescence imaging and subsequent clasper malposition. To prevent this complication, we updated our protocol in subsequent cases, including a mandatory repeat root angiography to confirm the position and configuration of the clasper after deployment. There were no valve dislodgements after that update.

Two patients underwent BPD for moderate to severe PVL due to frame underexpansion. Neither patient had no preoperative aortic stenosis. The degree of PVL was reduced to mild after BPD. A recent study concluded that BPD is safe and effective, and associated with an increased risk of neurologic events. ${ }^{28}$ In both patients, the significant PVL was related to clasper malposition resulting frame underexpansion. BPD might help expand the frame adequately and keep the frame and clasper in alignment.

For aortic stenosis, limited oversizing relative to the MDCT mean annular diameter and annular area is considered a reliable approach to reducing PVL. ${ }^{29-31}$ In this study, the MDCT mean annular diameter, MDCT annular area, and TTE diameter were all provided to the operator. Generally, the appropriate diameter of the prosthesis is considered to be $5 \%$ to $10 \%$ greater than the native annulus diameter derived from MDCT. However, operators were not obliged to follow this recommendation, but could choose the THV size they considered most appropriate. The maximal THV size available in this study was $27 \mathrm{~mm}$; however, annulus diameter is commonly larger in patients with pure aortic regurgitation compared with patients with aortic stenosis. Consequently, 23 of the 42 patients $(54.8 \%)$ had a THV undersized or oversized by $<5 \%$ related to MDCT mean annular diameter, and 15 of 37 patients $(40.5 \%)$ had a THV undersized or oversized by $<5 \%$ related to MDCT annular area. Owing to the clip mechanism of the clasper for additional fixation, this degree of oversizing appears to be sufficient to provide secure anchoring and thus minimize PVL. As a result, the limited oversizing reduced the incidence of annulus rupture and postprocedural conduction disturbance in our cohort. No patient experienced annulus rupture or second valve implantation in the index procedure. At the 1-year follow-up, only 2 of 39 patients $(5.1 \%)$ had a new permanent pacemaker implanted and 1 patient $(2.6 \%)$ had PVL of more than mild degree. These complications are less frequent than reported in another study using first-generation self-expanding valves. ${ }^{5}$ In this study, the THV was available in 4 sizes: $21,23,25$, and $27 \mathrm{~mm}$, which fit native annulus diameters of 19 to $26 \mathrm{~mm}$. Given the larger annulus in patients with aortic regurgitation, the manufacturer has now made a $29-\mathrm{mm}$ valve available, and $31-\mathrm{mm}$ valve is under study.

One patient with bicuspid aortic valve had moderate PVL after the procedure and died of congestive heart failure 25 days later. Bicuspid aortic valve was a relative contraindication in the preliminary program for the J-Valve. The patient was in NYHA grade IV with a left 
ventricular ejection fraction of $27 \%$ and a left ventricular end-diastolic diameter of $80 \mathrm{~mm}$. He was deemed at prohibitive risk for SAVR and in need of an urgent TAVR procedure to save his life. During the procedure, the positioning of the clasper was influenced by the raphe of the valve, which resulted in moderate PVL. As described previously, ${ }^{13}$ the clasper has 3 straight portions $120^{\circ}$ apart from one another that correspond to the native commissures, and curved portions that correspond to the cusps. The annulus and the clasper form a "lock-and-key" unit, which facilitates anatomic positioning. Precise positioning of the clasper depends greatly on the symmetrical morphology of the annulus and commissures, especially in patients with aortic regurgitation, who lack the calcification to provide additional anchoring. However, the other patient with bicuspid aortic valve in this study had trivial PVL after THV implantation and an uneventful recovery, and no PVL at the 1-year follow-up. We recommend that J-Valve implantation be carefully considered in patients with bicuspid aortic regurgitation without calcification. During the implantation procedure, the clasper configuration should be carefully inspected before the THV is deployed. In contrast, in patients with severe calcified aortic stenosis, including bicuspid valve and other pathologies, anchoring does not depend on the clip mechanism, supporting the use of the J-Valve in these patients.

As mentioned previously, ${ }^{13}$ the most significant differences between the J-Valve and other second-generation THVs are the 3-prong clasper and the movable connection between the frame and the clasper. The lock-and-key relationship of the clasper and annulus results in precise positioning of the clasper. Once the clasper is positioned into the sinus, it becomes a marker of the noncalcified annulus on fluorescence. The movable connection provides a 2-stage deployment, which enables adjustment of the THV according to the clasper. Both the depth into the LVOT and the coaxiality within it can be controlled easily and leisurely during THV deployment. The series of special designs helped overcome the challenges of TAVR for aortic regurgitation and contributed to the low mortality and morbidity in our cohort.

\section{Study Limitations}

This study has several limitations. It was a nonrandomized observational study without a control group. Only 43 patients were enrolled. The longest follow-up period was limited to 1 year. Future randomized studies or propensity score match analyses with more cases, longer follow-up, and control groups for comparisons with conservative treatment and SAVR are needed.

\section{CONCLUSIONS}

After an initial demonstration of feasibility, this multicenter study with up to 1-year follow-up has shown encouraging outcomes of transapical implantation of the
J-Valve device in patients with predominant aortic regurgitation. Continued observation is warranted to confirm persistent valve function during long-term follow-up.

\section{Conflict of Interest Statement}

Authors have nothing to disclose with regard to commercial support.

\section{References}

1. Kapadia SR, Leon MB, Makkar RR, Tuzcu EM, Svensson LG, Kodali S, et al. 5-year outcomes of transcatheter aortic valve replacement compared with standard treatment for patients with inoperable aortic stenosis (PARTNER 1): a randomised controlled trial. Lancet. 2015;385:2485-91.

2. Mack MJ, Leon MB, Smith CR, Miller DC, Moses JW, Tuzcu EM, et al. 5-year outcomes of transcatheter aortic valve replacement or surgical aortic valve replacement for high surgical risk patients with aortic stenosis (PARTNER 1): a randomised controlled trial. Lancet. 2015;385:2477-84.

3. Deeb GM, Reardon MJ, Chetcuti S, Patel HJ, Grossman PM, Yakubov SJ, et al. 3-year outcomes in high-risk patients who underwent surgical or transcatheter aortic valve replacement. J Am Coll Cardiol. 2016;67:2565-74.

4. Frerker C, Schewel J, Schewel D, Wohlmuth P, Schmidt T, Kreidel F, et al. Expansion of the indication of transcatheter aortic valve implantation: feasibility and outcome in "off-label" patients compared with "on-label" patients. J Invasive Cardiol. 2015;27:229-36.

5. Roy DA, Schaefer U, Guetta V, Hildick-Smith D, Möllmann H, Dumonteil N, et al. Transcatheter aortic valve implantation for pure severe native aortic valve regurgitation. J Am Coll Cardiol. 2013;61:1577-84.

6. Testa L, Latib A, Rossi ML, De Marco F, De Carlo M, Fiorina C, et al. CoreValve implantation for severe aortic regurgitation: a multicentre registry. EuroIntervention. 2014;10:739-45.

7. Schlingloff F, Schäfer U, Frerker C, Schmoeckel M, Bader R. Transcatheter aortic valve implantation of a second-generation valve for pure aortic regurgitation: procedural outcome, haemodynamic data and follow-up. Interact Cardiovasc Thorac Surg. 2014;19:388-93.

8. Seiffert M, Bader R, Kappert U, Rastan A, Krapf S, Bleiziffer S, et al. Initial German experience with transapical implantation of a second-generation transcatheter heart valve for the treatment of aortic regurgitation. JACC Cardiovasc Interv. 2014:7:1168-74.

9. Wendt D, Kahlert P, Pasa S, El-Chilali K, Al-Rashid F, Tsagakis K, et al. Transapical transcatheter aortic valve for severe aortic regurgitation: expanding the limits. JACC Cardiovasc Interv. 2014;7:1159-67.

10. Schofer J, Nietlispach F, Bijuklic K, Colombo A, Gatto F, De Marco F, et al Transfemoral implantation of a fully repositionable and retrievable transcatheter valve for noncalcified pure aortic regurgitation. JACC Cardiovasc Interv. 2015;8: 1842-9.

11. Kiefer P, Seeburger J, Mohr FW, Holzhey DM. Transcatheter aortic valve replacement for isolated aortic valve insufficiency: experience with the Engager valve. J Thorac Cardiovasc Surg. 2014;147:e37-8.

12. Zhu D, Chen Y, Guo Y, Hu J, Zhang J, Wei X, et al. Transapical transcatheter aortic valve implantation using a new second-generation TAVI system, J-Valve, for high-risk patients with aortic valve diseases: initial results with 90-day follow-up. Int J Cardiol. 2015;199:155-62.

13. Wei L, Liu H, Zhu L, Yang Y, Zheng J, Guo K, et al. A new transcatheter aortic valve replacement system for predominant aortic regurgitation: implantation of the J-valve and early outcome. JACC Cardiovasc Interv. 2015;8:1831-41.

14. Zhu D, Wei L, Cheung A, Guo Y, Chen Y, Zhu L, et al. Treatment of pure aortic regurgitation using a second-generation transcatheter aortic valve implantation system. J Am Coll Cardiol. 2016;67:2803-5.

15. Luo X, Wang X, Li X, Wang X, Xu F, Liu M, et al. Transapical transcatheter aortic valve implantation using the J-valve system: a 1-year follow-up study. J Thorac Cardiovasc Surg. 2017;154:46-55.

16. Rosenhek R, Iung B, Tornos P, Antunes MJ, Prendergast BD, Otto CM, et al. ESC working group on valvular heart disease position paper: assessing the risk of interventions in patients with valvular heart disease. Eur Heart J. 2012;33: 822-8. 828a, 828b.

17. Kappetein AP, Head SJ, Généreux P, Piazza N, van Mieghem NM, Blackstone EH, et al. Updated standardized endpoint definitions for transcatheter aortic valve implantation: the Valve Academic Research Consortium 2 consensus document. J Am Coll Cardiol. 2012;60:1438-54. 
18. Nishimura RA, Otto CM, Bonow RO, Carabello BA, Erwin JP III, Guyton RA, et al. 2014 AHA/ACC guideline for the management of patients with valvular heart disease: a report of the American College of Cardiology/American Heart Association task force on practice guidelines. J Am Coll Cardiol. 2014;63: e57-185.

19. Mehta RL, Kellum JA, Shah SV, Molitoris BA, Ronco C, Warnock DG, et al. Acute kidney injury network: report of an initiative to improve outcomes in acute kidney injury. Crit Care. 2007;11:R31.

20. Cribier A, Eltchaninoff H, Bash A, Borenstein N, Tron C, Bauer F, et al Percutaneous transcatheter implantation of an aortic valve prosthesis for calcific aortic stenosis: first human case description. Circulation. 2002;106:3006-8.

21. Popma JJ, Adams DH, Reardon MJ, Yakubov SJ, Kleiman NS, Heimansohn D, et al. Transcatheter aortic valve replacement using a self-expanding bioprosthesis in patients with severe aortic stenosis at extreme risk for surgery. J Am Coll Cardiol. 2014;63:1972-81.

22. Reardon MJ, Adams DH, Kleiman NS, Yakubov SJ, Coselli JS, Deeb GM, et al. 2-year outcomes in patients undergoing surgical or self-expanding transcatheter aortic valve replacement. J Am Coll Cardiol. 2015;66:113-21.

23. Nishimura RA, Bonow RO, Carabello BA, Erwin JP, Fleisher LA, Jneid H, et al. 2017 AHA/ACC focused update of the 2014 AHA/ACC guideline for the management of patients with valvular heart disease: a report of the American College of Cardiology/American Heart Association task force on clinical practice guidelines. Circulation. 2017;135:e1159-95.

24. Webb JG, Sathananthan J. Transcatheter aortic valve replacement for pure noncalcific aortic regurgitation is coming, but not yet primetime. JACC Cardiovasc Interv. 2016;9:2318-9.

25. Koschyk D, Seiffert M, Conradi L, et al. Transcatheter aortic valve implantation for non-calcified pure aortic insufficiency: initial results and follow-up. Catheter Cardiovasc Interv. 2014;83:S211-2.
26. Webb JG, Htun N. Transcatheter options for the treatment of noncalcified aortic regurgitation. JACC Cardiovasc Interv. 2015;8:1850-3.

27. Franzone A, Piccolo R, Siontis GC, Lanz J, Stortecky S, Praz F, et al. Transcatheter aortic valve replacement for the treatment of pure native aortic valve regurgitation: a systematic review. JACC Cardiovasc Interv. 2016;9: 2308-17.

28. Harrison JK, Hughes GC, Reardon MJ, Stoler R, Grayburn P, Hebeler R, et al. Balloon post-dilation following implantation of a self-expanding transcatheter aortic valve bioprosthesis. JACC Cardiovasc Interv. 2017; 10:168-75.

29. Binder RK, Webb JG, Willson AB, Urena M, Hansson NC, Norgaard BL, et al. The impact of integration of a multidetector computed tomography annulus area sizing algorithm on outcomes of transcatheter aortic valve replacement: a prospective, multicenter, controlled trial. J Am Coll Cardiol. 2013;62:431-8.

30. Willson AB, Webb JG, Labounty TM, Achenbach S, Moss R, Wheeler M, et al. 3-dimensional aortic annular assessment by multidetector computed tomography predicts moderate or severe paravalvular regurgitation after transcatheter aortic valve replacement: a multicenter retrospective analysis. J Am Coll Cardiol. 2012;59:1287-94.

31. Jilaihawi H, Kashif M, Fontana G, Furugen A, Shiota T, Friede G, et al. Cross-sectional computed tomographic assessment improves accuracy of aortic annular sizing for transcatheter aortic valve replacement and reduces the incidence of paravalvular aortic regurgitation. J Am Coll Cardiol. 2012;59:1275-86.

Key Words: transcatheter aortic valve replacement, aortic regurgitation, transcatheter heart valve

Readers who found these articles interesting may also like to read the following papers found in recent and future issues of our sister publications, Seminars in Thoracic and Cardiovascular Surgery and Operative Techniques in Thoracic and Cardiovascular Surgery!

\section{Adult: Valve}

ORIGINAL SUBMISSION: Early Outcomes for Valve-in- Valve TAVR in Degenerative Freestyle Bioprostheses. Stephane Leung Wai Sang. Semin Thoracic Surg 2017: In press.

ORIGINAL SUBMISSION: Complications after Self- Expanding Transcatheter or Surgical Aortic Valve Replacement. John V. Conte. Semin Thoracic Surg 2017: 321-330. 